\title{
Management of Patient Primigravida 36-37 Weeks with Chronic Myeloid Leukemia, Anemia, and Thrombocytopenia
}

\author{
Muhammad Farlyzhar Yusuf ${ }^{\varpi^{*}}$, Ruddi Hartono *,**
}

Article Info :

Submitted :

27-08-2021

Accepted :

17-10-2021

Published :

30-10-2021

https://dx.doi.org/10.2096

1/soja.v1i2. 54703

Authors' affiliations:

*Department of

Anesthesiology and

Intensive Therapy,

Medical Faculty,

Universitas Brawijaya,

Malang

${ }^{* *}$ Dr. Saiful Anwar

Hospital, Malang

${ }^{\otimes}$ Correspondence:

farlyzhar@gmail.com

\begin{abstract}
Chronic myelogenous leukemia (CML) is a type of cancer caused by a disturbance in the hematopoietic stem cells. CML itself rarely occurs on women in labor, and an advanced procedure in this condition has become a special challenge for medics, especially an anesthesiologist. We describe the circumstance of CML in pregnancies is performed by cesarean section with general anesthesia. The first pregnant patient was 36 weeks of pregnancy; the patient was first diagnosed with CML at 26-28 weeks of pregnancy. At that time, the patient complained of frequent dizziness, abdominal pain, and weakness. Moreover, the patient complained of bleeding gums and nosebleeds. The bone marrow analysis showed a condition of accelerated phase of CML (suspected atypical CML) with nutritional deficiency. We performed general anesthesia technique of Rapid Sequence Intubation with regimen of fentanyl $100 \mathrm{mcg}$, propofol $80 \mathrm{mg}$ and rocuronium $50 \mathrm{mg}$. The patient was admitted to the ward for two days before transferring to the intensive care unit (ICU). The patient received intravenous paracetamol 1 gram every six hours a day, cefazolin 1 gram twice a day, lansoprazole $30 \mathrm{mg}$ once a day, tranexamic acid 1gr three times a day, and 15 mcg per hour fentanyl continuously. The hemodynamic status of patient in the ICU were in a stable condition. On the second day of postoperative care, the patient was transferred to the high care unit (HCU), then at the third postoperative day, the patient's hemodynamics were stable, and the patient was transferred to a general ward.
\end{abstract}

Keywords: CML; general anesthesia; pregnancy 


\section{INTRODUCTION}

Chronic myelogenous leukemia (CML) is a type of cancer caused by a disturbance in the hematopoietic stem cells. CML is a form of leukemia characterized by an uncontrolled increase and growth of myeloid cells in the bone marrow. CML is a clonal bone marrow stem cell disorder with a proliferation of mature granulocytes (neutrophils, eosinophils, and basophils) and their precursors. This condition is a type of myeloproliferative disease with a chromosome translocation called the Philadelphia chromosome.

The incidence of chronic myelocytic leukemia reach $15 \%$ of all types of leukemia in adults. According to Surveillance, Epidemiology End Results, and Medical Research data, CML is more likely to occur at 53-60 years, but the average age reported is 40 years, although it can be found at a younger age and is usually more progressive. The cause of CML remains unclear, with the critical role of genetic and environmental factors, such as radiation exposure and so on ${ }^{2}$.

On the female, the incidence of CML in a year could reach $0.6-1.6$ in 100.000 populations; therefore, CML may also occur in women in labor age and at a younger age. In pregnant women, CML is very rare with incidence of 1: 75000 cases. In the end, this would have been a special case where special treatment is needed for this disease management ${ }^{3}$.

The threatened life of mother and fetus should be the main consideration for a pregnant woman with CML. Therefore, CML management on pregnancy should pay attention to a specific challenge for Hematologists, Obstetricians and Anesthetists, particularly in dealing with physiological changes during pregnancy, anemia, immunosuppressant therapy, leukocytosis, and thrombocytopenia. Hence, it is necessary to develop standardized management guidelines for this disease $^{4}$.

The low incidence of CML in pregnancy limits the development of standard anesthesia guidelines, so we describe the circumstance of CML in pregnancies performed by cesarean section with general anesthesia.

\section{CASE ILLUSTRATION}

A 20-year-old female was examined for her 36-week pregnancy 
check-up, and she complained of headache, stomachache, dizziness, gum bleeding, and nosebleed. She was diagnosed with chronic myeloid leukemia (CML) on 26-28 weeks of pregnancy.

Afterwards, Obstetrician plans a section cesarean for her aterm pregnancy. According to the preoperative anamnesis, she explained that her family did not have a history of CML and no history of routine drugs consumption. According to the physical examination, her respiration, cardiovascular, neurological, gastrointestinal, and urinary function were normal.

$$
\text { Based on laboratory }
$$
examination, we found anemia with hemoglobin 3,4 gr/dl, thrombocytes $7000 \mathrm{~mm}^{3}$, leukocytes $15.560 \mathrm{~mm}^{3}$, and hematocrit 9,7\%. According to blood smear evaluation, it was found that normochromic anisopoikilositosis for erythrocyte, elliptocyte, macro ovalocyte, leucocyte count increased, myeloblast (+), Pseudopelger huet anomaly, neutrophil (+), and thrombocyte count decreased with giant thrombocyte + . Other tests were iron serum 286, TIBC 297, and transferrin
$96 \%$. Laboratory examination is shown in Table 1.

The Bone Marrow evaluation showed that there was a high number in leukocyte $\left(27.460 \mathrm{~mm}^{3}\right)$ with low hemoglobin 7,5 g/dl and low thrombocyte $17.000 \mathrm{~mm}^{3}$. According to peripheral blood count, the activity of the granulocyte cell was significantly increased; the distribution was like the 14\% myeloblastic, low erythropoiesis, with M:E ratio was 100:1. This result concluded that the patient was in an accelerated phase and had a blast cell of more than $10 \%$ but less than $20 \%$. Therefore, there was a chronic myeloid leukemia in the acceleration phase (Suspect CML atypical) with nutritional deficiency.

We concluded her physical status as ASA 3, Gravida 36-37 weeks, Chronic myeloid leukemia, anemia, and thrombocytopenia. On the preoperative preparation for elective section cesarean procedure, we administered blood component transfusion to the patient with thrombocyte count target that is higher than $50.000 \mathrm{~mm} 3$ and hemoglobin that is higher than $8 \mathrm{gr} / \mathrm{dl}$. We evaluated the blood count test after transfusion, and the target was reached (hemoglobin 10,5 gr/dl, hematocrit 
$30,7 \%$, and thrombocyte count 75.000 $\mathrm{mm} 3)$. Thus, we prepared for section cesarean procedure.

Anesthesia management option for this patient was general anesthesia with rapid sequence intubation technique, and the regimen was fentanyl $100 \mathrm{mcg}$, propofol $80 \mathrm{mg}$, rocuronium $50 \mathrm{mg}$. The duration of the section cesarean procedure was 1 hour, with an inhalational agent was sevoflurane, and the baby was born with an APGAR score of $6 / 8$.
After section

caesarean

procedure, the patient was evaluated in the ICU for 2 days with administration of paracetamol 1 gram/6 hours and continuous infusion of fentanyl 15 $\mathrm{mcg} /$ hour for pain management without any complication. After two days, the patient was moved to the obstetric care ward without any complaint. The patient condition in ICU was shown in Figure 1.

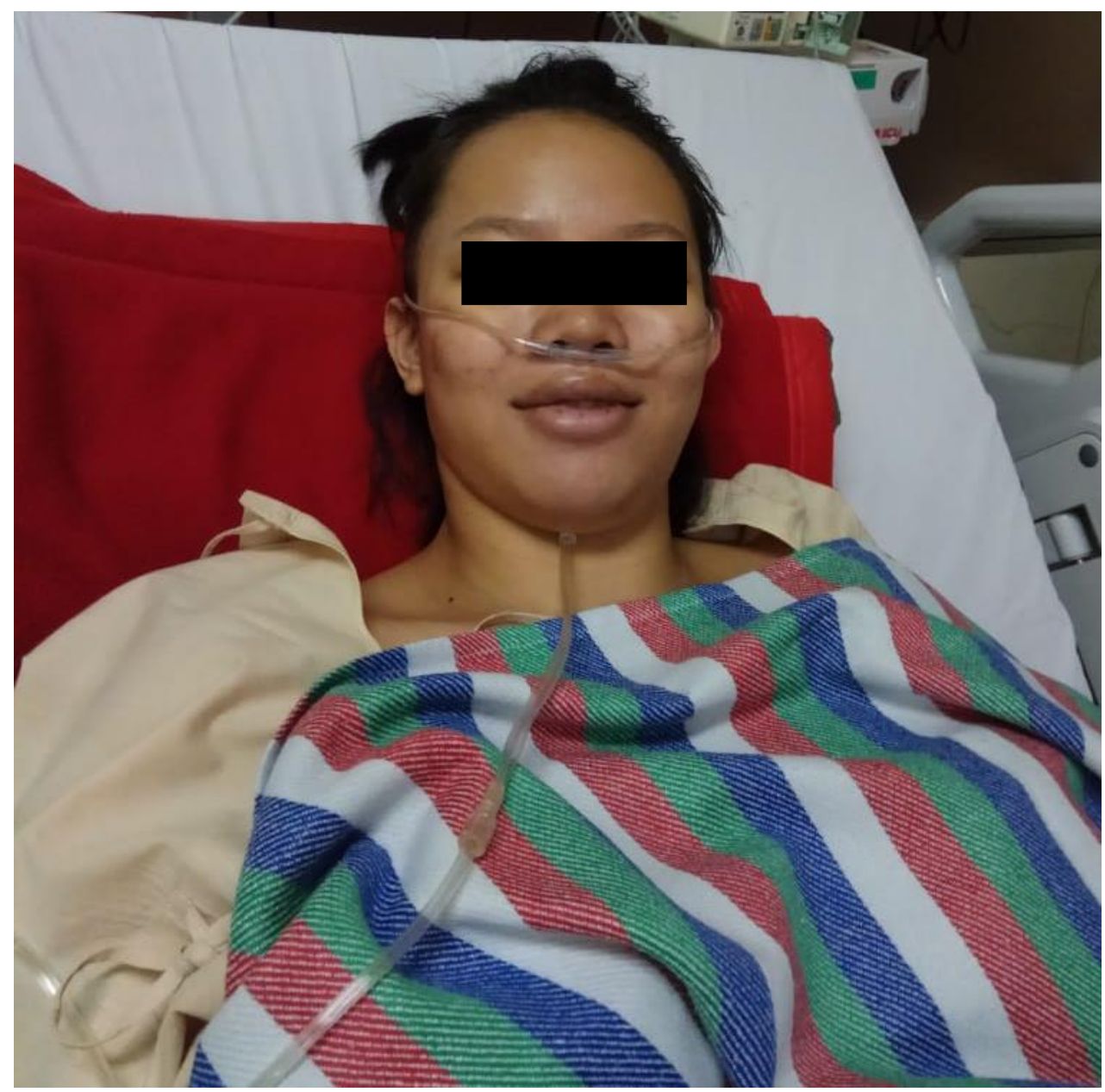

Figure 1. Post Operative patient at ICU 



\section{DISCUSSION}

Good anesthesia management and selection of appropriate anesthesia measures must be performed in pregnant patients with CML since the preoperative phase. In addition to clinical evaluation and investigations, we must evaluate the history of the disease and chemotherapy in the patient $^{5}$.

CML (Chronic myeloid leukemia) in pregnancy is very rare, with an incidence of 1: 75000 cases, and further management in this situation is a special challenge for doctors $^{3}$. The case of CML with pregnancy was found in this case, yet she was diagnosed lately at 26-28 weeks of gestation or during the third trimester, where the patient had complaints of bleeding of gums, weakness, and abdominal pain. This situation can occur in cases of CML where the disease is divided into 3 phases, namely the chronic phase, acceleration, and the blast crisis phase. In the chronic phase, patients sometimes have asymptomatic as their clinical manifestation. Continuously, the symptoms will develop when it enters the accelerated phase, which is explained in this phase. The complaints arise can be shown as bleeding gums, weakness, and abdominal pain. This situation occurs due to neoplastic myeloid proliferation that suppress the production of other blood elements due to competition for nutrients for metabolic processes (thrombocytopenia occurs resulting in bleeding in various places, including epistaxis, menorrhagia $)^{6,7}$.

Over time, the patient was referred to the hospital and evaluated for the bone marrow examination. The results of bone marrow examination showed increase activity of granulocyte cell which concluded that the patient was in an accelerated phase. In this phase, the number of leukocytes can reach until 300 thousand $/ \mathrm{mm}^{3}$, which is dominated by eosinophils and basophils ${ }^{6}$.

The most anticipated condition in CML patients with pregnancy is the occurrence of a crisis blast or the third phase of CML, where myeloblast cells circulate $>30 \%$ in the circulation, which will result in rapid clinical deterioration and worsened high mortality. Moreover, there was a possibility of complications of CML that resulted in IUGR. 
Table 1. Laboratory results

\begin{tabular}{|c|c|c|c|c|c|c|c|c|}
\hline Laboratory & $\begin{array}{c}15 \text { Jan } \\
2020\end{array}$ & $\begin{array}{c}16 \text { Jan } \\
2020\end{array}$ & $\begin{array}{c}17 \text { Jan } \\
2020\end{array}$ & $\begin{array}{c}19 \text { Jan } \\
2020\end{array}$ & $\begin{array}{c}20 \text { Jan } \\
2020\end{array}$ & $\begin{array}{c}21 \text { Jan } \\
2020\end{array}$ & $\begin{array}{c}\text { 21 Jan } \\
2020 \\
\text { Post OP }\end{array}$ & $\begin{array}{c}22 \text { Jan } \\
2020\end{array}$ \\
\hline $\mathbf{H b}$ & 3.40 & 4.10 & 5.90 & 8.20 & 9.60 & 10.50 & 10.3 & 11.4 \\
\hline Ht & $9.70 \%$ & $11.70 \%$ & $17.30 \%$ & $24.0 \%$ & $28.50 \%$ & $30.70 \%$ & $30.00 \%$ & $32.8 \%$ \\
\hline $\mathbf{L}$ & 15.560 & 14.960 & 13.740 & 12.370 & 14.920 & 15.900 & 20.450 & 20.760 \\
\hline $\mathbf{T r}$ & 7.000 & 12.000 & 12.000 & 33.000 & 46.000 & 73.000 & 108.000 & 90.000 \\
\hline Reticulosis & & $0.24 \%$ & & & & & & \\
\hline $\begin{array}{l}\text { Reticulosis } \\
\text { Absolut }\end{array}$ & & 3500 & & & & & & \\
\hline $\begin{array}{l}\text { Immature } \\
\text { Platelet } \\
\text { Fraction }\end{array}$ & & $30.7 \%$ & & & & & & \\
\hline Alb & 3.36 & & & & & & 3.33 & \\
\hline OT & 15 & & & & & & & \\
\hline PT & 22 & & & & & & & \\
\hline $\mathbf{U r}$ & 21.9 & & & & & & & \\
\hline $\mathrm{Cr}$ & 0.82 & & & & & & & \\
\hline GD & & & 101 & & & & & \\
\hline $\mathbf{N a}$ & & & & 135 & & & 135 & \\
\hline $\mathbf{K}$ & & & & 3.52 & & & 3.64 & \\
\hline Cl & & & & 113 & & & 110 & \\
\hline Ca & & & & & & & 8.5 & \\
\hline PTT & $9.70 / 10.9$ & & & $9.80 / 10.7$ & & $\begin{array}{c}10.20 / 10 \\
7\end{array}$ & $9.90 / 10.7$ & \\
\hline APTT & $\begin{array}{c}23.20 / 24 \\
9\end{array}$ & & & $\begin{array}{c}24.40 / 25 \\
2\end{array}$ & & $\begin{array}{c}28.40 / 25 \\
5\end{array}$ & $\begin{array}{c}28.50 / 25 \\
5\end{array}$ & \\
\hline INR & 0.93 & & & 0.94 & & 0.98 & 0.95 & \\
\hline Iron & & & & & & & & \\
\hline TIBC & 212 & & & & & & & \\
\hline $\begin{array}{l}\text { Transferrin } \\
\text { Saturation }\end{array}$ & $99 \%$ & & & & & & & \\
\hline
\end{tabular}


Therefore, the final decision was to execute a cesarean section for this patient. However, there are other challenges in managing this patient, where there are other comorbidities in the form of anemia, thrombocytopenia with clinical bleeding in the form of epistaxis. Therefore, anesthetic preparation must be appropriate before surgery; the platelet count below $50,000 \mathrm{~mm}^{3}$ will increase bleeding during surgery. Before the procedure, the cesarean section patient must be transfused until it reaches a target platelet above $50,000 \mathrm{~mm}^{3}$ and adequate blood preparation during the operation must be handled ${ }^{8}$.

This patient does not have a history of chemotherapy because her disease was discovered in the third trimester. Then, a particular challenge for anesthesiologists is the choice of anesthesia technique, in which we must consider the phase of CML disease because the blast crisis in the literature mentions a contraindication to spinal anesthesia or neuraxial block. After all, lumbar manipulation can present a risk of blast cell invasion of the cerebral fluid, which leads to a poor prognosis ${ }^{9}$. In addition, the patient's thrombocytopenia creates the risk of massive subcutaneous bleeding in the neuraxial block technique $e^{4,10}$. Therefore, in this patient, the general anesthesia technique was chosen because it was safer considering the patient's CML and other comorbid conditions ${ }^{9}$.

The common cause for all these obstetric complications is placental insufficiency because of the leukocytosis resulting from the uncontrolled myeloproliferation seen in CML, and hence, if left untreated during pregnancy, then chances of lowbirth-weight babies, fetal prematurity, and maternal/perinatal mortality are increased. An understanding of normal maternal-fetal physiology is critical in the diagnosis, surgical and anesthesia management, and postoperative care of pregnant women. Leukocytosis and thrombocytosis lead to increase in blood viscosity, which may increase the risk of infection, thromboembolic events, and hemorrhage ${ }^{4}$. In this case, the patient had not had severe complication, however, the APGAR score resulted in a normal score (6-8) even though could not reach the maximum condition. 
Post-operative

complication

within section caesarian in $\mathrm{CM}$ patient can be formed as massive subcutaneous hemorrhage resulting from multiple epidural punctures in patient with thrombocythemia due to CML. Therefore, patient in this case was managed by general anesthesia technique. Moreover, two cases of thrombocytosis due to myeloproliferative disease was reported where general anesthesia was given along with epidural block in a patient who received myelosuppressive therapy resulting in normal platelet count and only general anesthesia in the second patient with increased platelet count ${ }^{4}$.

In this patient, no complication was reported after the section caesarian procedure. The hemodynamic status of patient in the ICU were in a stable condition. On the second day of postoperative care, the patient was transferred to the high care unit (HCU), then at the third postoperative day, the patient's hemodynamics remained stable, and the patient was transferred to a general ward.

\section{CONCLUSION}

Management of CML patients with pregnancy requires the proper collaboration of a hematologist, oncologist, obstetrician, and anesthesiologist in order to carry out safe management of patients, even with a variety of comorbid and complications that occur in patients, proper management will help good results in patients. In the case described, general anesthesia is a safe choice in pregnancy with CML accompanied by anemia and thrombocytopenia.

\section{REFERENCE}

1. Sawyer C. Chronic Myeloid Leukimia. N Engl J Med. 1999;340:1330-40.

2. Rohrbacher M, Hasford J. Best Practice \& Research Clinical Haematology Epidemiology of chronic myeloid leukaemia ( CML ). Best Pract Res Clin Haematol. 2009;22(3):295-302.

3. Owsiak JN, Bullough AS. Chronic myeloid leukemia in pregnancy: An absolute contraindication to neuraxial anesthesia? Int J Obstet Anesth. 


\section{$2016 ; 25: 85-8$}

4. Ganeriwal V, Agrawal P, Thote P, Parkar M, Waiker SS. Anesthesia consideration for cesarean section in chronic myeloid leukemia diagnosed during pregnancy: An interesting case report and brief review of literature. 2019;99-102.

5. Turgeon ML. Clinical Hematology Theory and Procedures. fifth edit. Baltimore: Lippincott Williams \& Wilkins, a Wolters Kluwer business; 2012. 294-306 p.

6. Cancer.org. What is Chronic Myeloid Leukemia? Am Cancer Soc. 2016;(Cml):1-10.

7. Butterworth JF, Mackey DC, John D. Wasnick. Morgan \&
Mikhail's

Clinical

Anesthesiology. 6th editio. New

York; 2018. 2070-2086 p.

8. Hines RL, Marschall KE. Stoelting's ANESTHESIA AND CO-EXISTING DISEASE. seventh ed. Philadelphia: Elsevier; 2018. 605-609 p.

9. Rebahi H, Ait Sliman M, El Adib A-R. Chronic Myeloid Leukemia and Cesarean Section: The Anesthesiologist's Point of View. Case Rep Obstet Gynecol. 2018;2018:1-3.

10. Ghatak T, Singh RK, Samanta S. Anesthesia for a patient with thrombocytosis. Saudi J Anaesth. 2013;7(4):479-80. 